Revista Iberoamericana, Vol. LXXII, Núms. 215-216, Abril-Septiembre 2006, 515-529

\title{
CANIBALISMO Y MODERNIDAD: LA HISTORIA COMO PLATO PRINCIPAL
}

POR

\author{
KARINA Miller \\ University of California, Irvine
}

\begin{abstract}
Comúnmente [los españoles] mataban a los señores y nobles [indios] de esta manera: que hacían unas parillas de varas sobre horquetas, y atábanlos en ellas y poníanle por debajo fuego manso, para que poco a poco, dando alaridos en aquellos tormentos desesperados, se les salían las ánimas (Bartolomé de las Casas, Brevísima Relación de la Destrucción de las Indias 28)
\end{abstract}

Me temo que nuestros ojos son más grandes que nuestros estómagos, y que tenemos más curiosidad que entendimiento. Agarramos todo, pero no asimos nada más que viento (Montaigne, Essays "On Cannibals”, 106). ${ }^{1}$

En 1929 el Manifiesto Antropofágico brasileño de Oswald de Andrade acuñó su famosa frase: "Tupi or not Tupi, that is the question". ${ }^{2}$ La cuestión de la identidad aparece aquí encarnada en la escisión fundamental de la diferencia con el Otro. Si la figura del caníbal es una construcción del discurso colonialista, ${ }^{3}$ entonces el procedimiento de la vanguardia brasileña es hacerse cargo de este efecto del lenguaje: la cuestión pasa por cómo nos representamos a nosotros mismos. Al recuperar la agencia, al representarse a sí mismo, el movimiento de vanguardia se vuelve político. ${ }^{4} \mathrm{He}$ aquí la vuelta de tuerca de

\footnotetext{
${ }^{1}$ La traducción es mía.

${ }^{2}$ Tupí es el nombre de las tribus que habitan el amazonas brasileño y que son relacionadas frecuentemente con la práctica de la antropofagia. Hans Staden, autor del libro que nos ocupa en este trabajo, fue cautivo por los Tupinambás por nueve meses y la Vera Historia narra sus desventuras como prisionero de éstos.

${ }^{3}$ Para un análisis de la construcción de la figura del caníbal en el discurso colonial véase el artículo de Carlos Jáuregui.

${ }^{4}$ Vale la pena reflexionar en uno de los puntos para repensar la política que propone Alain Badiou en relación con una ética: "El abandono de la representación en la política”: “En las políticas de representación no puede haber ética, pues para un sujeto, la acción ética es justamente aquella que no puede ser representada. En la ética el sujeto se presenta a sí mismo” (32). Véase también “Sujeción y Subjetivación” de Etienne Balibar, en El reverso de la diferencia: Identidad y Política.
} 
un viaje que parte para América y que no termina con las narraciones de los viajeros del siglo XIX como la de Richard Burton, autor de la introducción a la edición inglesa del libro de Hans Staden (que incluye un extenso relato de su propio viaje, trescientos años más tarde, por las mismas tierras brasileñas que recorrió el viajero alemán), y que se define por una inversión de términos. Estos relatos de la conquista atestiguaron un mundo que, además de “nuevo” era virgen de representación, un significante excesivo en significaciones que requirió de un conjunto de estrategias discursivas que se hizo cargo de constituir la diferencia. Diferencia, entonces, se vuelve el otro polo de identidad. El eje discursivo identidad -diferencia presupone siempre una jerarquía histórica que el Movimiento Antropofágico brasileño revierte. El problema de la identidad nacional es encarado por el Movimiento Antropofágico con la lógica del reflejo: lo que el espejo muestra es una imagen y esa imagen es tomada como una verdad; seamos pues, el monstruo del espejo, devoremos la historia y hagamos nuestra propia digestión; ese es el discurso de la vanguardia brasileña: una cuestión ética que apunta a revertir la vieja dicotomía dominadosdominantes. El hecho de que la vanguardia sea un movimiento estético limpia el horizonte histórico de residuos científicos y de pretensiones de verdad: el discurso queda por fin completamente del lado del lenguaje (¿es que no lo estaba antes?) y es en ese gesto lúdico que el discurso colonial se muestra en su desnudez: por fin el indio le devuelve, con una carcajada, los espejitos de colores al europeo desconcertado.

La importancia de la figura del caníbal toma aquí una dimensión múltiple que desarma las jerarquías de poder; si bien todo comenzó con el “descubrimiento” y la conquista algo se perdió en el camino de la historia: el propósito de este trabajo es rastrear las inversiones, los movimientos y las sustituciones en la representación del otro que se produjeron en el discurso colonial, tomando como referencia el texto de Hans Staden escrito en 1556 en Alemania de vuelta de su viaje por América en donde fue prisionero por nueve meses de los indios Tupinambá del Brasil, y cómo esta problemática es retomada por el movimiento modernista brasileño a principios del siglo xx, invirtiendo los términos de la ecuación colonial.

La distinción entre antropofagia como una “categoría científica”, y caníbal como construcción discursiva nos interesan aquí sólo como síntoma de una “enfermedad” del discurso; ésta es la necesidad de legitimación de prácticas de dominación en el contexto de la conquista y colonización de América. ${ }^{5}$ Este trabajo se ocupará solo de la segunda: caníbal es el otro absoluto; una figura móvil y dinámica que se traslada en la jerarquía dominante-dominado asumiendo los dos polos de la dicotomía según una economía discursiva interna, caníbal es un significante imposible, caníbal es, alternativamente, objeto y sujeto. Esta movilidad del significante caníbal adquiere importancia en tanto desestabiliza jerarquías y vuelve imposible la representación del otro como una identidad inmutable; si el caníbal es la representación del otro absoluto, lo es en tanto interioridad o posibilidad, su amenaza reside en lo irrealizable de su eliminación: no siendo exterioridad canibalismo es un virus que ataca la identidad.

Balibar anota: "Por último, una proposición ética: el valor de la acción humana reside en que nadie puede ser liberado o emancipado por otros, aunque nadie pueda liberarse sin los otros, tesis que siempre ha señalado el momento de "sublevarse"” (192).

${ }^{5}$ Ver William Arens. 
LA NARRACIÓN DE LA HISTORIA

En el principio fue el Verbo. El verbo como presencia. El verbo creador del mundo y la palabra como testigo:

Así yo, tras larga pena, peligro de cuerpo y vida he arribado de nuevo, tras el curso de varios años, al principado de Vuestra Principesca Merced, mi intensamente querida patria, y he querido comunicar sumisamente este mi viaje y navegación la que he redactado lo más sucintamente por si V.P.M quisiese leer en ella acerca de tierras y mar recorridas por mí con la ayuda de Dios... Para que V.P.M. no dude de mí como yo presentara cosas no verídicas, quise ofrecer yo mismo a V.P.M. un pasaporte apropiado a este relato. (Staden 2)

El relato de Staden se estructura sobre dos ejes principales que se complementan y superponen: Dios y la verdad. Si Dios permitió que Staden volviera a su tierra natal fue porque tenía un propósito en mente: Staden fue testigo y su misión es narrar la historia. La Vera Historia es la prueba tanto de la existencia de Dios como de la existencia del caníbal, los dos insertos en el mismo sistema de verdad, dos polos que no se sostienen el uno sin el otro:

De esta misma manera yo agradezco al Todopoderoso Creador del cielo, tierra y mar, a su hijo/Jesucristo y al Espíritu Santo por la magna gracia y misericordia que a mí entre los hombres salvajes del país de Tupinambá que me habían cautivado -comen carne humana, de ellos fui prisionero durante nueve meses-y en muchos otros peligros más me han ocurrido por la Santa Trinidad en un modo milagroso completamente inesperado. (2)

Nótese la valoración en la representación del otro que se produce en este fragmento: primero los "hombres salvajes” de un país extraño “Tupinambá”; luego el suplemento de sentido: “comen carne humana”. La diferencia con el otro se hace doble, el estadio salvaje todavía comparte la humanidad humana, sin embargo, el agregado "comen carne humana” los aleja un paso más allá, más allá de los salvajes en el mundo de lo irrecuperable y lo increíble. La ingestión de carne humana transforma al otro en el otro del otro. Peter Hulme en su libro Colonial Encounters anota:

Los hombres que comen otros hombres han sido siempre ubicados en los bordes mismos de la humanidad. No son considerados inhumanos, porque si fueran animales su comportamiento sería natural y no provocaría la violencia y el temor que el 'canibalismo' siempre ha provocado.

'Canibalismo': la palabra sale fácil, sin problemas; una palabra directa sin ambigüedades problemáticas, más familiar (y fácil de pronunciar) que la alternativa 'antropofagia’. (14, traducción mía)

Las diferencias, entonces, se construyen sobre una ordenación jerárquica que ubica al caníbal en el umbral de la humanidad. Lo demasiado no humano, se podría decir, invirtiendo la frase nietzscheana. 
Entre los dos polos del discurso de La Vera Historia -Dios y Caníbal- el relato se postula como verdad; de aquí en adelante el lector debe creer: la existencia del caníbal se produce como una cuestión de fe. En El monolingüismo del otro, Jacques Derrida, refiriéndose al testimonio, dice:

[P]uesto que no se puede dar testimonio más que de lo increíble. En todo caso, de lo que solamente puede ser creído, de lo que, tras pasar por alto la prueba, la indicación, la constatación, el saber, apela únicamente a la creencia, por lo tanto a la palabra dada. Cuando uno pide que crean su palabra está, quiéralo o no, sépalo o no, en el orden de lo que sólo es creíble. Se trata siempre de lo que se ofrece a la fe [...] de lo que es únicamente “creíble” y por ende tan increíble como un milagro. [...] Esa verdad supone la veracidad, incluso el falso testimonio, y no a la inversa. (34-35)

Esta certidumbre de la que hablábamos más arriba, la creencia de la existencia del caníbal, es la contracara de la fe en Dios y es en éste sistema de analogías que se busca la verdad del texto. En palabras de Michel de Certeau: “A Dios y al caníbal, igualmente elusivos, el texto les asigna el rol de la Palabra, en cuyo nombre se ubica la escritura -pero también el rol de un lugar constantemente alterado por el '(t)exterior' inaccesible que autoriza la escritura” (Heterologies 69, traducción mía). Desde este punto de vista tanto el caníbal como dios autorizan al texto, lo vuelven posible, y al mismo tiempo son exteriores a él. En la exterioridad del discurso, esto es, lo que queda fuera del discurso, pero a lo cual el discurso alude, está la "verdad” inasible. La carta de D. Dryander que precede el texto de Staden en la versión en español y la introducción de Richard Burton en la versión inglesa son síntomas visibles de una imposibilidad de representación que intenta curarse en la repetición incansable de códigos, en la pretensión de llenar un vacío de saber con conocimiento y experiencia. Dryander enumera varias razones por las cuales debemos creer en el texto de Staden, una muy importante es que:

Y un argumento para mí muy serio de que su causa y la descripción de esta historia deben ser sinceras es que él indica el tiempo, ciudad y lugar donde Heliodorus, hijo del sapientísimo y celebérrimo Eobanus Hess, que hace mucho tiempo se ha marchado a visitar tierras extrañas y entre nosotros fue tenido por muerto, ha estado con éste Juan Staden en el país de las gentes salvajes y ha visto cuán miserablemente fue hecho prisionero y alejado. Este Heliodorus -digo yo- puede volver a su casa dentro de poco o mucho tiempo (como se espera que suceda) y si la historia de Juan Staden fuera falsa e inventada puede él avergonzarlo y declararlo hombre vano. (4)

El discurso de Staden va más allá de sí mismo creando un sistema de repetición que atestigua "la" verdad: primero Dios, luego Staden, los caníbales y los testigos secundarios como Heliodorus y Dryander. Además en la versión en español se publican los (impresionantes) grabados de los dibujos del mismo Staden. La estrategia discursiva de Burton en la versión inglesa se basa también en la experiencia como eje legitimador del relato (aunque el binomio Dios-verdad es reemplazado por ciencia-verdad) agregando una extensa (casi de la misma extensión que el relato de Staden) introducción con su propia experiencia en Brasil; un relato de viaje hecho por él mismo trescientos años más tarde. 
La diferencia que se produce en estos trescientos años de distancia entre la narración de Staden y de Burton está encarnada en esta última en la copiosa cantidad de notas al pie (a veces el espacio de la página está ocupado casi enteramente por la nota al pie dejando sólo un pequeño lugar para el relato en sí) que explican la etimología de las palabras, los nombres de las plantas y animales, el origen de las costumbres y las diferentes acepciones en los diccionarios, enciclopedias y tratados de los distintos autores aludiendo a todo un aparato de conocimiento externo (al texto de viaje) típico del siglo XIx (La diferencia entre el texto de viaje de Staden y el de Burton requeriría en si misma un análisis aparte). Trescientos años más tarde, entonces, el discurso imperialista cambia a Dios por la ciencia en un movimiento excesivo que una vez más apela a la repetición (de citas, de apéndices, de bibliografía) e intenta crear una clara diferencia entre lo que el propio discurso es y lo que no es. Lo que queda claro es que en la insistencia en la veracidad de los acontecimientos, las estrategias retóricas, y el aparato de conocimiento que apoyan ambas versiones (en español y en inglés) de la Vera Historia se trata de una economía de la diferencia, encarnada en un nosotros y un ellos. Si bien la representación de este contraste que aparece en el discurso colonialista e imperialista ha sido extensamente analizada, lo interesante aquí es que la repetición que marca la diferencia es un efecto exterior del discurso que encubre una falacia interior a éste: la imposibilidad de representar algo que, no siendo exterioridad pura, se vuelve posibilidad. Esta posibilidad involucra la identidad y la relación entre sujeto y objeto.

Vera Historia y Descripción de un País de las Salvages Desnudas y Feroces Gentes Devoradoras de hombres Situado en el nuevo mundo de América: en el mismo título se condensa la repetición y la diferencia: Vera (verdadera) y descripción se complementan y se apoyan enfatizando la objetividad del relato (lo que está de este lado). La reiteración de “salvajes”, “desnudas”, “feroces”, “devoradoras de hombres” marca la frontera: lo que está del otro lado; otro eslabón más en la cadena de repeticiones y excesos; el otro país, el otro mundo, el otro otro. Dijimos antes que la repetición, el exceso, forma parte de la estructura del discurso. Una táctica del discurso (es también una técnica para volverse creíble) que reclama la identificación. La repetición se vuelve una forma de clasificación, un ordenamiento. La identificación como resultado al que invoca el discurso encarna entonces un orden. Verdad, orden, fe: tres ejes del discurso que enmarcan la identificación con un nosotros o un ellos. Sin embargo, a pesar de la estructuración del discurso colonial, algo queda afuera de la representación; esto es la identidad. En palabras de Derrida: “Una identidad no es nunca dada, recibida o alcanzada; no, sólo se sufre el proceso interminable, indefinidamente fantasmático de la identificación” (44). Y más adelante menciona: “El yo se habría formado, entonces, en el sitio de una situación inhallable, que siempre remite a otra parte, a otra cosa, a otra lengua, al otro en general” (47). Mientras el lector avanza en la lectura de la Vera Historia se encuentra con un Staden emplumado, atado, pelado, aterrorizado, vuelto mago y brujo, hablando la lengua del otro. ¿Es esa la misma voz que escribe la Vera Historia? ${ }^{6}$ Hay, en la trayectoria del viajero colonial (esto se puede ver

\footnotetext{
${ }^{6}$ Resulta interesante en este punto la reflexión que hace Angel Loureiro en su libro The Ethics of Autobiography con respecto a la autobiografía como un "acto preformativo" y no simplemente una reproducción de la vida, sino una recreación del yo en el acto de escribir. Loureiro en una lectura
} 
también en relatos como, por ejemplo, el de Cabeza de Vaca) un punto de inflexión que suspende el viaje y ese punto es el cautiverio.

$\mathrm{Si}$, como propone Georges Van Den Abbele, "El viajero piensa en su viaje en términos de destino (punto de llegada) o de punto de partida” (xviii, traducción mía), el cautiverio desafía la racionalidad del viaje en tanto el regreso al hogar, al oikos, ${ }^{7}$ queda suspendido en la incertidumbre. El cautiverio produce un doble movimiento, como su etimología lo indica: "Cautivar: Aprisionar: cautivar al enemigo. Fig. Atraer, ganar: cautivar a su auditorio. Fig. Ejercer irresisitible influencia (SINÓN. Captar, seducir, hechizar, embelesar. Fig. Conquistar. V. Tb. Gustar)" y "Cautivo: adjetivo y sustantivo: Prisionero” (Diccionario Pequeño Larousse Ilustrado 101). Cautivar es a la vez un ejercicio de fuerza y seducción, el cautiverio se hace irresistible. Se cautiva al enemigo, aquel que representa una amenaza, y se lo fuerza hasta la fascinación. El hechizo al que alude la definición de cautiverio comparte el sentido con conquistar (también portadora de cierta ambigüedad de sentido entre fuerza y embriaguez) y gustar. Es en el cautiverio donde el virus del canibalismo ataca más fuerte: el encantamiento del otro se vive en carne propia. Algo se invierte en la suspensión del cautiverio: de conquistador a conquistado.

LA METAMORFOSIS

En "Ius Factum: Text and Experience in the Writings of Bartolome de Las Casas" Anthony Pagden reproduce un diálogo imaginario, escrito por Pedro Francisco de Quiroga en 1555 entre dos personajes: Barchilon, que hace tiempo que ha llegado al nuevo mundo, y Justino, un recién llegado:

Abre los ojos y verás que todo es el reverso de lo que ves en Castilla. Lo que aparentan ser correspondencias, son, de hecho, inversiones. No te involucres con las cosas de esta tierra hasta que las entiendas, porque son cuestiones diferentes, y otro lenguaje; dice Barchillon. El nuevo monje tiene que aprender a hablar de nuevo. Para Barchillon es la inconmensurabilidad la que es, en definitiva, la única certeza. (87, traducción mía)

Desde este punto de vista, entonces, el "Nuevo Mundo” sería, en realidad, el “mundo invertido"; un negativo del mundo. Llegar a América es como pasar a través del espejo. Sin embargo del otro lado no hay un reflejo de uno mismo sino una transformación. Este pasaje se produce con plena intensidad en el cautiverio. El cautivo (el europeo cautivo), en el territorio del otro se transforma él mismo en el otro. Esa transformación ubica al

de Paul Eakin indica que éste caracteriza la autobiografía como "a type of self invention at the moment of writing that parallels the individual's acces to identity at the moment of acquisition of language” (1). Esto se podría también pensar para el discurso de Staden, donde el sujeto se re-crea en el acto mismo de escribir.

${ }^{7}$ Según Van Den Abeele: "In order to have an economy of travel, some fixed point of reference must be posited. The economy of travel requires a oikos (the Greek for "home" from which is derived “economy”) in relation to which any wandering can be comprehended (enclosed as well understood). In other words: home(land) must be posite from which one leaves the journey and to which one hopes to return... The posit of an oikos or domus (the latin translation to oikos), is what domesticates the voyage by ascribing certain limits to it” (xviii). 
sujeto en el umbral de la identidad; parte de un ciclo que llega a su fin en el regreso, en la propia tierra, oikos, y en la escritura. La escritura es el oikos, el hogar al que se vuelve, la fuerza, la jerarquía, la historia. La escritura es el uno; la experiencia es el otro. Todo empieza con el cambio de nombre:

\begin{abstract}
Cuando éstos vieron que me traían corrieron todos a su encuentro. Estaban adornados con plumas a su usanza y mordían en sus brazos y me amenazaban que así iban a comerme. Y delante de mí iba un rey con un palo con el cual matan a los cautivos. Este peroraba y decía cómo ellos habían prendido a mí, su esclavo, el perot (así llamaban a los portugueses) y ahora iban a vengar a mí la muerte de sus amigos [...] Ahí estaba yo parado y oraba y miraba tras de mi temiendo el golpe pero [...] el rey que quiso tenerme y dijo que ellos me llevaran vivo al pago [...] y me ataron cuatro cuerdas en derredor del cuello y yo tuve que entrar en una canoa mientras ellos estuvieron en tierra. Y ellos ataron las puntas de las cuerdas a la canoa y empujaron de nuevo al mar para navegar de vuelta a sus pagos. (47)
\end{abstract}

Como se refiere anteriormente, Derrida señala que la identidad no es nunca algo dado, que el yo está siempre en situación: es en este sentido que el discurso construye un sujeto. Sin embargo éste es siempre un sujeto interior al discurso; esto es: definido por una movilidad. En la cita de Vera Historia se puede rastrear un movimiento que traslada al sujeto conquistador como conquistado: a Staden se le atribuye primero otro nombre: esclavo, perot (portugués), el cambio de sujeto a objeto está ya dado; queda solamente atarlo a la canoa para comenzar el viaje (el otro viaje) al cautiverio.

En la lectura que De Certeau hace del ensayo de Montaigne “Of Cannibals”, éste señala que el discurso de Montaigne interroga sobre "el estatus de lo extraño” y que, al mismo tiempo, el texto se presenta como una narrativa del espacio que postula, simultáneamente, su propio lugar y el lugar del otro. El texto deviene "testigo" del otro. $\mathrm{Al}$ analizar la estructura del ensayo de Montaigne, de Certeau toma en cuenta el relato de viaje y escribe:

Primero está la partida: la búsqueda de lo extraño, la cual se presume diferente del lugar asignado en el comienzo por el discurso cultural. Esta diferencia a priori, el postulado del viaje, resulta en una retórica de la distancia en los relatos de viaje. Se ilustra por una serie de sorpresas e intervalos (monstruos, tormentas, lapsos de tiempo, etc.) que, al mismo tiempo, confirman la alteridad del salvaje, y autorizan al texto a hablar desde otro lado, para imponer su credibilidad. (69, traducción mía)

La diferencia a priori de la que habla de Certeau es, en el caso de la Vera Historia, un límite que se construye con la escritura y un umbral que se cruza con la experiencia. Si bien la experiencia es una experiencia del discurso, puesto que todo es escritura en la Vera Historia, es precisamente lo que se escapa al discurso, la "inconmensurabilidad" de la que habla Padgen; lo que pertenece al "orden de lo que sólo es creíble, puesto que no se puede dar testimonio más que de lo increíble”. ${ }^{8}$

${ }^{8}$ Ver cita de Derrida del Monolingüismo del Otro. 


\begin{abstract}
Cuando yo vine a tierra no pude ver pues yo estaba golpeado debajo de los ojos, tampoco pude caminar bien y tuve que estar echado en la arena a causa de la herida que tenía en la pierna. Ellos estaban parados en mi derredor y me amenazaban de cómo iban a comerme. Ahora cuando yo estaba así en gran angustia y desconsuelo, pensé sobre lo que antes jamás consideré, es decir sobre el triste valle de penas en el cual vivimos aquí y comencé a cantar con los ojos lagrimeantes desde el fondo de mi corazón el salmo: desde profunda angustia clamo a Ti, etc. Entonces dijeron los salvajes: vean cómo él grita, ahora está desconsolado [...] Ellos ataron arriba de un árbol las cuerdas que yo tenía en el cuello y se acostaron en mi en derredor de la noche, hacíname burlas/y me llamaron en su lengua: che remimbaba inde tú eres mi animal atado. (Staden 50-51, énfasis mío)
\end{abstract}

Las palabras de los Tupinambás que cita aquí el texto de Staden se reproducen en dos lenguas: la lengua de los Tupinambás tiene el poder de cautivar al enemigo, la fuerza salvaje posee el poder de la inversión: la animalidad del otro es una cuestión de posicionamiento del discurso. Tupinambá es la lengua que define, la situación de identidad; el español (alemán en el original) la traducción. La traducción forma parte de un sistema de conocimiento y de translación. La idea de translación puede ser vista a la luz del concepto de “contact zone” acuñado por Mary Louise Pratt en su libro Ojos imperiales. "Contact zone” se refiere a un contacto (particular) entre dos culturas:

Uso esa expresión [zona de contacto] para referirme al espacio de los encuentros coloniales, al espacio en que pueblos geográfica e históricamente separados entran en contacto y establecen relaciones duraderas, relaciones que usualmente implican condiciones de coerción, radical desigualdad e insuperable conflicto.

[...] En mi exposición "zona de contacto" es con frecuencia sinónimo de "frontera colonial”. [...] Al usar la palabra "contacto" pretendo llevar a primer plano las dimensiones interactivas y de improvisación de los encuentros coloniales [...] Desde este punto de vista, no se abordan las relaciones entre colonizadores y colonizados, o entre viajeros y "visitados" en función de la separación o el apartheid (la separación racial), sino en términos de copresencia, de interacción, de una trabazón de comprensión y prácticas, muchas veces dentro de relaciones de poder radicalmente asimétricas. (27)

Esta perspectiva no deja de lado la dicotomía dominantes-dominados sino que la vuelve permeable: “contact zone” refiere a una porosidad en la jerarquía de la diferencia y cuestiona la rigidez de las identidades colonizador-colonizado. El cautivo vive en carne propia este contacto cultural que, en el caso particular del cautiverio, se traduce en una momentánea inversión de términos. Es decir: en el cautiverio invertido ${ }^{9}$ no sólo se produce una "copresencia”, una "interacción” a la que se refiere la zona de contacto; sino que el verdadero "encuentro" se da en una situación que combina a la vez la desigualdad y la transformación. Contacto en el cautiverio implica al mismo tiempo la violencia y el

${ }^{9}$ Con el término cautiverio invertido nos referimos a una situación en la cual el dominante pasa a ser dominado, en este caso el europeo conquistador se vuelve esclavo de los indios. Es importante recalcar esta diferencia, puesto que el análisis es diferente para la situación de cautiverio "convencional" en donde el indio, o el africano, es esclavo. En esta situación el entorno político, social y cultural, además del geográfico, en el cual el traslado es impuesto, tiene una influencia completamente diferente en la identidad del cautivo. 
encantamiento que produce el otro y que se da en esa instancia particular. Contacto sería, entonces, en el discurso de la Vera Historia, transformación; proceso identificatorio; suspensión del viaje; interioridad. El contacto siempre es un contacto interior; esto es: no se da en el intercambio de objetos, o de bienes; no se da en la guerra o el enfrentamiento de fuerzas; se da en la compleja relación de inversión en donde el conquistador se vuelve conquistado. En el cautiverio invertido la "zona de contacto” es pura interioridad.

"En esta plantación de raíces andaban muchas de sus mujeres y arrancaban raíces; a ésas tuve que gritar en su lengua: Ayu-iche-be ene remiuram- eso es: -yo, vuestra comida, llega" (52-53). Aquí se puede ver el desplazamiento por el cual el sujeto se ha transformado en objeto. El ritual que ha comenzado con el cambio de nombre y la soga al cuello se traduce en una serie de cambios externos que apuntan a una transformación:

\begin{abstract}
Allí estuve yo en medio y dos mujeres a mi lado ataron contra la pierna con un cordón varias cosas que castañeteaban y me ataron también atrás/ en la nuca un disco hecho de colas de aves- era cuadrada- que me pasara la cabeza y se llama en su lengua arazoya. Entonces el mujerío todas juntas comenzó a cantar y al igual como sonara su son, debí yo pisar con la pierna en la cual me habían atado las sonajeras para que yo castañeteara y sonara... (56)
\end{abstract}

HUMANO, DEMASIADO HUMANO

A partir de la subversión de términos en la situación de dominación es donde se puede rastrear cómo el significante caníbal reviste la inconmesurabilidad de una diferencia que pertenece al orden del discurso colonial. Para el europeo el otro es el caníbal, para los Tupinambás el otro es el enemigo; lo interesante aquí es el código ético que gobierna la práctica del canibalismo, lo cual no puede decirse de la práctica del conquistador. Véase, este párrafo de Bartolomé de las Casas en su Brevísima Descripción de la Destrucción de las Indias:

Todas estas universas e infinitas gentes, a todo género crió Dios los más simples, sin maldades ni dobleces, obedientísimas [...] sin rencores y odios, sin desear venganzas que hay en el mundo. Son asimismo las gentes más delicadas, flacas y tiernas en complición [...] Su comida es tal, que la de los Santos Padres en el desierto no parece haber sido más estrecha ni menos deleitosa ni pobre [...] En estas ovejas mansas y de las calidades susodichas, por su hacedor y creador así dotadas, entraron los españoles [...] como lobos y tigres y leones crudelísimos de muchos más días hambrientos. Y otra cosa no han hecho de cuarenta años a esta parte hasta hoy, y hoy en día lo hacen, sino despedazarlas, matarlas, angustiarlas, afligirlas, atormentarlas y destruirlas por las extrañas y nuevas y varias y nunca otras tales vistas ni leídas ni oídas, maneras de crueldad [...]” (24, énfasis mío)

Este código ético que se mencionó anteriormente es un código de honor; Staden agrega a la narración de su cautiverio un apéndice llamado "Vera y sucinta relación de tratos y costumbres de los Tupinambá cuyo cautivo he sido; habitan en América [...]” (107) en donde narra las costumbres, la organización política y social, la religión, etc. de los indios del Brasil. En un apartado llamado “Porqué come un enemigo a otro” dice: 
Ellos lo hacen no por hambre sino de gran odio y ojeriza y cuando ellos en la guerra escaramucean entre ellos grita el uno al otro en odio: "De t'mbaerba che remiú rama mae amboe” a ti sobrevenga toda desfortuna, mi comida; Nde canga yuca cýpotá curimé; yo quiero romper tu cabeza aun hoy día; che y anama pepique qui cha icú; para vengar en ti la muerte de mis amigos/ estoy aquí; rendé zoó moquen sera coaracy cyma riré etc. Tu carne será hoy día antes que entre el sol mi asado. Todo eso lo hacen por gran enemistad. (132)

Y luego en otro apartado llamado "Lo que es su mayor honor” anota: "Su honor es esto: cuando uno ha cautivado y muerto muchos enemigos pues eso es usual entre ellos. Cuantos enemigos mata a uno, tantos nombres se da a él y los más principales ente ellos son aquellos quienes tienen muchos de tales nombres” (128). Nótese como en el primer párrafo el enemigo es "mi comida”, con esta denominación el sujeto pasa primero en el plano de lo simbólico a ser objeto, para luego ser, en la práctica, comido. El comer carne humana, entonces, se vuelve parte de un código de honor que el europeo no comparte y que, paradójicamente, lo animaliza, ya que, como se vio anteriormente en el párrafo de Bartolomé de las Casas, el hambre es el motor de la conquista. Aquí se ve la doble paradoja del canibalismo: la oposición ética-crueldad se da en la inversión de términos salvajeeuropeo; porque, si la ética es lo que rige el código de honor del canibalismo de los Tupinambas y que, sin embargo, los separa de la humanidad humana, la crueldad es lo que define la humanidad del europeo y lo constituye como sujeto humano.

Me preguntó ese que también tenía parte sobre mí, llamado Alguindar si yo había visto ahora cómo ellos trataban a sus enemigos. Entonces dije: sí- eso que vosotros los coméis, me parece horroroso pero matarlos no es tan horroroso. -Sí- dijo él- esa es nuestra costumbre, así hacemos también a los portugueses. (75)

Y este Conian Bebe tenía delante de sí un gran cesto lleno de carne humana, comió de una pierna, me la tuvo delante de la boca [y] me preguntó si yo quería comer también. Yo dije: -un animal irrazonable difícilmente come al otro ¿Comería entonces un ser humano al otro?- El mordió en ella y dijo: -yaguará iché- yo soy un tigreanimal- sabe bien- Con esto me retiré de él. (92)

Comer a los enemigos es horroroso, pero matarlos no tanto. Eliminar al otro está bien; incorporarlo, no. Ésta es la lógica de la conquista. La respuesta de Conian Bebe a Staden será la consigna que el movimiento antropofágico brasileño recuperará casi cuatrocientos años después.

Otra VUelta DE TUerca

La Revista de Antropofagia se publica en Brasil desde mayo de 1928 a febrero de 1929. En Las Vanguardias Latinoamericanas. Textos Programáticos y Críticos, Jorge Schwartz anota:

Dos fases o “denticiones” marcan la trayectoria de la Revista de Antropofagia [...] La presencia de Oswald de Andrade es notoria, pues la revista refleja consistentemente el ideario antropofágico. 
[...] Y así como el cristianismo inauguró una nueva era, la antropofagia funda su propio tiempo. [...] Hay una revisión del indianismo tradicional alencariano y un regreso a lo primitivo, distanciado, sin embargo, de los presupuestos europeizantes del bon sauvage rousseauniano. La antropofagia no tiene nada que ver con el romanticismo indianista. $\mathrm{Al}$ indio hijo de María, al indio hermano del Santísimo, al indio degradado por la catequesis, del que nos habla Couto de Magalhares, oponemos al caníbal, que devoró al catecismo y le dijo a Hans Staden que no molestase, porque era sabroso. El indio desnudo. (262) ${ }^{10}$

El Manifiesto Antropofágico le da otra vuelta de tuerca a la historia. Si el caníbal es el otro del europeo y el europeo define su humanidad por la crueldad, entonces el caníbal recupera su "mayor honor” y se dispone a afilar los dientes y agregarle un nombre más a la lista.

REPRESENTACIÓN Y DIFERENCIA

Representación y diferencia son dos ejes que están profundamente conectados en el discurso de la modernidad brasileña, así como también el de la cuestión de la identidad. “Tupí or not Tupí” es una pregunta ontológica por la esencia del ser pero además es una pregunta por la continuidad de la historia. La frase de Oswald de Andrade entonces, es una puesta en cuestionamiento de la esencia del ser Brasileño (ser Tupí o no ser Tupí) y de la posibilidad de traducción: ¿es posible una identidad nacional que se traduzca en lo universal? (that is the question). Estos ejes discursivos: identidad, diferencia, continuidad; delimitan una cuestión ética: ¿cómo representarse a sí mismo? El discurso colonial pone en escena la cuestión de la representación de la diferencia; al intentar representar la diferencia entre dos mundos queda siempre una brecha, un intersticio que hace evidente la imposibilidad de representación. El caníbal es este intersticio. Caníbal está en el umbral de la representación. En otras palabras el problema de la representación trae consigo el de la identidad, un cuestionamiento ético que traspasa la frontera de lo estético y deviene político.

El hombre natural que nosotros elegimos puede tranquilamente ser blanco, vestir saco y andar en avión. Como también puede ser negro y hasta indio. Por eso lo nombramos "antropófago" y no tontamente "tupí" o "parecí”. No vamos a utilizar nuestra ofensiva con grabados de taparrabos ni disparates de boleadoras. Esto puede figurar como elemento decorativo y sensacional de nuestra bajada; sin dudas y gustosamente nos reportamos a la época en que, en el azar de este continente, el hombre realizaba en el hombre la operación central de su destino: el devoramiento directo del enemigo valiente (transformación del tabú en tótem). (Oswald de Andrade, "Pronominare” 535) 11 $^{11}$

Caníbal, entonces, puede ser cualquiera de nosotros. El nacionalismo del discurso cultural autóctono, que se define por la exageración de rasgos que conforman la identidad

\footnotetext{
${ }^{10}$ Publicado en Las Vanguardias Latinoamericanas; textos programáticos y críticos. Todas las citas ya traducidas provienen de este libro.

${ }^{11}$ Reproducido de Las Vanguardias Latinoamericanas.
} 
nacional en una suerte de metonimia (de ahí la mención al “taparrabos” y las “boleadoras”) no resulta un alimento atractivo para el caníbal. Caníbal es universal. Es una máquina devoradora de historia.

Frente al discurso cultural europeo estigmatizado por el germen del discurso colonial (en sus variantes del buen salvaje y el exotismo primitivo) el Movimiento Antropofágico niega la continuidad de la historia y revierte la marca de la representación: “Teníamos la justicia, codificación de la venganza. La ciencia, codificación de la magia. Antropofagia. La transformación permanente del Tabú en tótem” (Oswald de Andrade 146). La transformación de tabú en tótem marca decisión ética de la negación de una representación histórica que se transforma en alimento para la identidad nacional brasileña.

En "Tupy or not Tupy: Cannibalism and Nationalism in Contemporary Brazilian Literature an Culture”, Randall Johnson anota y parafrasea:

\begin{abstract}
En Oswald de Andrade, la idea del caníbal se usó para escandalizar, para amenazar la imaginación del lector con la posibilidad de su resurgencia permanente. Como lo nota Benedito Nunes, la palabra antropofagia fue usada como arma verbal, como un instrumento de agresión personal y como un arma ofensiva con resonancias explosivas. 'Es una palabra catalizadora, reactiva y elástica, en la cual la práctica del canibalismo, el devorar antropofágico, es un símbolo sangriento, una mezcla de insulto y sacrilegio, de desprecio y flagelo público, como un sustituto verbal de la agresión física contra un enemigo de muchas caras’. (50, traducción mía)
\end{abstract}

Esta idea de canibalismo como "amenaza”, como posibilidad de "resurgimiento permanente” se vuelve también, en el discurso de la modernidad brasileña, un discurso de identidad nacional.

HAMBRE DE MODERNIDAD

Sérgio Luiz Prado Bellei en su análisis del movimiento antropofágico, escribe:

La influencia de la práctica crítica y literaria de los hermanos Campos puede ser definida como lo que Haroldo Campos llama "transculturación”, una práctica que, siguiendo la propuesta de Andrade, apunta a 'pensar lo nacional, en su relación dialógica con lo universal'. Consiste, desde su punto de vista, en la actividad de devorar discursos extranjeros. [...] La antropofagia es definida por los hermanos Campos como una continuación y una reducción drástica de los esfuerzos ambiciosos de Andrade. La idea de incorporar discursos extranjeros permanece, pero restringida a la producción de artefactos culturales de valor estético. (101, traducción mía)

El proyecto del movimiento antropofágico de Oswald de Andrade se extiende no sólo al campo de lo estético, sino a un más amplio espectro que incluye lo social, lo cultural y lo político. Como lo define Roberto Schwarz: “[es una] interpretación triunfante del atraso brasileño" (101). ${ }^{12}$ Desde este punto de vista el modernismo brasileño (y en general el modernismo en América Latina), dividido entre la realidad social y el deseo de lo moderno

\footnotetext{
${ }^{12}$ Parafraseado por Prado Bellei. La traducción es mía.
} 
como expresión de adelantos tecnológicos y de una sociedad industrializada, se constituye en esta diferencia y realiza un doble movimiento: al hacer explícito el hambre de modernidad se desvía de la dicotomía discursiva impuesta por la representación colonial y se vuelve positividad.

Según Carlos Alonso la modernidad trajo consigo una narrativa de futuridad en la cual el mundo se identificó inequívocamente con el futuro. En América Latina esta narrativa de futuro coexistió con un modelo importado de nación; esta dicotomía, sugiere Alonso, promovió una crisis en la cual el escritor latinoamericano produjo una retórica discursiva en la búsqueda de legitimación de su posición frente a la amenaza de la modernidad. Alonso analiza cómo en un movimiento centrífugo el escritor latinoamericano crea al mismo tiempo una distancia con ese discurso de la modernidad y mantiene su poder discursivo. La ambivalencia, entonces, se constituye como base del discurso de la modernidad latinoamericana. La ambivalencia con respecto a la historia, esto es: la constitución del discurso de la modernidad basado en la polaridad de valores opuestos, sería el punto en el cual la continuidad -la futuridad- de la historia se detiene. "Contra las historias del hombre, que comienzan en el Cabo Finisterra. El mundo no fechado. No rubricado. Sin Napoleón. Sin César” (Reproducido en Las Vanguardias Latinoamericanas 148). Como se mencionó anteriormente el Movimiento Antropofágico se vuelve máquina devoradora de historia. En este devorar se incorpora y se hace desaparecer -he aquí la ambigüedad- la continuidad del discurso histórico. "Contra la Memoria fuente de la costumbre. La experiencia personal renovada” (Reproducido en Las Vanguardias Latinoamericanas 151). Entonces sí hay un futuro, sin embargo, ese futuro es otro. La positividad reside en la amenaza; el peligro de comer y dejarse comer por la historia.

El hambre es entonces, resistencia. Una opción ética que recupera la identidad nacional para volverla universal. Objeto se vuelve sujeto; y viceversa: si Hans Staden logró escapar de los Tupinambás; su discurso es finalmente devorado en un intento caníbal de digerir la historia. Para el movimiento antropofágico la transformación del conquistador no es nunca completa y la única “contact zone” posible es la de la digestión. Esto lleva a considerar la observación de De Certeau sobre el ensayo de Montaigne:

Lo que Montainge considera es el estatus de lo extraño. [...] ¿Cuál es el lugar del otro? Esta línea de pensamiento cuestiona el poder del texto de componer y distribuir un lugar, su habilidad de ser una narrativa del espacio y la necesidad de éste de definir su relación con lo que trata, en otras palabras, de construir un lugar propio. El espacio del otro es el espacio del texto. (67)

La vanguardia brasileña crea un espacio discursivo en el cual el estatus de lo extraño, la otredad del otro deviene agencia y se vuelve la única alternativa ética posible. Porque si bien el cautiverio invertido transforma al colonizador de sujeto en objeto, éste retorna al oikos y escribe la (vera) historia. El único colonizador que no retorna, parece sugerir el Movimiento Antropofágico, es el colonizador comido. Sólo que esta vez la carne humana es la metáfora de la historia:

La historia es canibalística y la memoria se vuelve el escenario de conflicto entre dos operaciones contradictorias: el olvido, que no es algo pasivo, una pérdida, sino una 
acción dirigida contra el pasado; y el trazo mimético, el retorno de lo que fue olvidado, en otras palabras, una acción del pasado que se esfuerza por distinguirse. (De Certeau 3, traducción mía)

Casi cuatrocientos años después el Movimiento Antropofágico se propone recuperar el significante caníbal y lo devuelve al orden de la interioridad. Se es caníbal por elección, caníbal se hace y no se nace: no se trata sólo de preferencias culinarias, se trata fundamentalmente de gustos éticos. Como menciona Jens Anderman en su artículo “Antropofagia: Testimonios y Silencios”: si el testimonio es un intento de reproducir las figuras de unos “otros” entonces antropofagia designaría los intentos de subvertir su representación.

Caníbal se vuelve boomerang. Caníbal se vuelve oikos interior. Pura posibilidad. No hay lugar al que volver cuando se es caníbal.

No al indio. El indianismo para nosotros es un plato de mucha sustancia. Como cualquier otra escuela o movimiento. De ayer, hoy y de mañana. De aquí y de afuera. El antropófago se come al indio y se come al llamado civilizado: sólo queda él lamiéndose los dedos. Dispuesto a engullirse a sus hermanos. [. ..] Al fin sobrará un Hans Staden. Ese Hans Staden contará aquello de lo que huyó y con sus dados se hará el próximo futuro. Antonio de Alcántara Machado. “Abre-Alas” (Reproducido de Las Vanguardias Latinoamericanas 265)

Si indio es el otro y caníbal el otro del otro, es entonces en el exceso de la diferencia que se vuelve imposible de representar donde se encontraría una posibilidad ética de resistencia, una inversión de los términos dominador-dominado. El discurso colonial ha representado al caníbal en el umbral de lo humano, sin embargo, la humanidad humana del conquistador europeo deja, inevitablemente, un resabio amargo en el paladar de la historia.

Esa gente es salvaje en el mismo sentido que decimos que las frutas son salvajes [...] en lo anterior, lo verdadero, más útil, y las virtudes y propiedades naturales están vivas y vigorosas; en lo último los hemos rebajado y adaptado sólo para gratificación de nuestro gusto corrupto. De todas maneras, hay una delicadeza y un sabor especial en algunas frutas no cultivadas de esas regiones que resulta excelente, incluso para nuestro paladar, y rivaliza con las nuestras. (Montaigne 109, traducción mía)

“Tupí or not Tupí: that is the question”: la cuestión ética de la identidad y la diferencia; sobre gustos hay demasiado escrito. 
BiBLiOgRAFÍA

Alonso, Carlos. The Burden of Modernity. New York: Oxford University Press, 1998. Andermann, Jens. “Antropofagia: Testimonios y Silencios”. Revista Iberoamericana 198 (2002): 79-89.

Badiou, Alain. Reflexiones sobre nuestro tiempo. Interrogantes acerca de la ética, la política y la experiencia de lo inhumano. Belo Horizonte: Ed. Del Cifrado, 1999.

Balibar, Ettiene. "Sujeción y Subjetivación”. El reverso de la diferencia. Identidad y política. Caracas: Nueva Sociedad, 2000. 181-195.

De Certeau, Michel. Heterologies. Discourse on the Other. Mineapolis: University of Minnesota Press, 1986.

Derrida, Jacques. El Monolingüismo del otro. Buenos Aires: Ediciones Manantial, 1997.

Hulme, Peter. Colonial Encounters. New York: Methuen, 1986.

Jáuregui, Carlos A. "Saturno Caníbal: Fronteras, Reflejos y Paradojas en la narrativa sobre el antropófago”. Revista de Crítica Literaria Latinoamericana 51 (Lima-Hanover, 1er. Semestre 2000): 9-39.

Las Casas, Bartolomé de. Brevísima descripción de la destrucción de las Indias. Buenos Aires: Ediciones Mar Océano, 1953.

Loureiro, Angel. The Ethics of Autobiography. Nashville: Vanderbilt University Press, 2000.

Montaigne, Michel de. Essays. Baltimore: Penguin Books, 1966.

Pagden, Anthony. "Ius et Factum: Text and Esperience in the Writings of Bartolomé de las Casas”. New World Encounters. Stephen Greenblatt, ed. Berkeley: University of California Press, 1993. 85-101.

Pratt, Mary Louise. Ojos imperiales: literatura de viajes y transculturación. Buenos Aires: Universidad Nacional de Quilmes, 1997.

Staden, Hans. Wernicke, Edmundo (trad.) Vera Historia y descripción de las salvages desnudas feroces gentes devoradoras de hombres situado en el Nuevo Mundo de América. Buenos Aires: Coni,1944.

The Captivity of Hans Stade of Hesse in A.D 1547-1555 Among the Wild Tribes of Brazil. Por Richard Burton. Albert Tootal, trad. New York: Burt Franklin, 1870.

Schwartz, Jorge. Las vanguardias latinoamericanas. Madrid: Ediciones Cátedra, 1991. Van Den Abbeele, Georges. Travel as Metaphor. From Montaigne to Rosseau. Minneapolis: University of Minnesota Press, 1992. 
